\title{
Evidence of Spontaneous Activity in Two Cases of Severe Myasthenia Gravis
}

Esther Annegret Pelzer ${ }^{1,4 *}$, Norbert Galldiks ${ }^{1,2}$, Carsten Eggers ${ }^{3}$, Anna Brunn ${ }^{3}$, Gereon Rudolf Fink ${ }^{1,2}$ and Walter Friedrich Haupt ${ }^{1}$

${ }^{1}$ Department of Neurology, University Hospital Cologne, Kerpener Str. 62, 50937 Cologne, Germany

${ }^{2}$ Forschungszentrum Jülich $\mathrm{GmbH}$, Wilhelm-Johnen-Straße D-52428 Jülich, Germany

${ }^{3}$ Department of Neuropathology, University Hospital Cologne, Kerpener Str. 62, 50937 Cologne, Germany

${ }^{4}$ Max-Planck Institute for Neurological Research Cologne, Gleueler Str. 50 D-50931 Cologne, Germany

\begin{abstract}
Electromyography is an important element of clinical diagnostics and often helps physicians to find the appropriate diagnosis between different neuromuscular disorders. By having a closer look on electromyographical findings in myasthenia gravis, myopathic changes predominantly occur in proximal muscles next to a pathological decrement, which can underscore the diagnosis of this neuromuscular disorder. In polymyositis, next to myogenic changes more often signs of spontaneous activity like fibrillations and complex repetitive discharges are found as signs of muscle inflammation.

Here, we present two cases of myasthenia gravis, which had with classical electrophysiological features of myasthenia gravis, but also showed pathological spontaneous activity in the electromyographical investigation next to muscle pain, which complicated the differential diagnosis to diseases like polymyositis.
\end{abstract}

Keywords: Spontaneous activity; Myasthenia gravis; Polymyositis; Concurrence

\section{Introduction}

Myasthenia gravis (MG) is a disease with a prevalence of $20 / 100000$ patients. It is caused by autoantibodies against postsynaptic acetylcholine receptors (AChR) or against muscle specific receptor tyrosine kinase (MuSK). The typical clinical manifestation can be divided into five grades (I-V; Myastenia Gravis Foundation of America (MGFA) classification) [1]. MGFA class I includes only ocular onset; class II includes mild generalised onset; class III includes moderate generalised onset; class IV includes severe generalized fatigue; class V patients need mechanical ventilation. For class II-IV a further classification in subclass ' $a$ ' indicates prevalent limb muscle involvement, while subclass ' $b$ ' includes patients with predominant bulbar muscle involvement.

Polymyositis (PM) is a more rare (incidence of 5-10/100000 patients per year) systemic auto-inflammatory disease of skeletal muscles with perivascular lymphocyte infiltration of cytotoxic CD8 (+) lymphocytes with MHC I positive fibres. In the pathophysiological cascade, cytotoxic T-cell-lymphocytes invade and destroy muscle cells. The resulting necrosis is caused by perforin granula, which is secreted by T-cells, in association with interferone gamma, interleukine-1 and TNF [2], the resulting clinical manifestation is symmetric proximal pure motor paresis often with myalgic pain and arthralgia. Concomitant malignant diseases are found in some cases [3]. In etiological classification systems, this disease belongs to the category of collagenoses.

Although the clinical profile and pathogenesis of MG and PM are quite different, they both share typical features of autoimmune diseases, e.g., the presence of autoantibodies, the fluctuating course of the disease, the association with other autoimmune disorders, and the effectiveness of immunosuppressive therapy. Moreover, PM is, though less frequently, accompanied by elevated AChR-antibodies [4]. However, myasthenic symptoms in patients with PM are a rare phenomenon [5-9].

Here, we report two cases of patients with MG, who had electromyographical and clinical features of PM.

\section{Patient \# 1}

A 58-year old woman was admitted to our hospital as an inpatient with a sore throat, dryness of the mouth, and dyspnoea and a progredient weakness of her muscles. Neurological examination revealed dysarthria, dysphagia and paresis of limb-girdle muscles and muscle pain of the proximal limbs. Deep tendon reflexes were regularly evoked. AChR-antibody levels were significantly increased $(110 \mathrm{nmol} / \mathrm{l})$. MuSK-antibody levels $(5.46 \mathrm{nmol} / \mathrm{l})$ and creatine kinase levels were normal (Table 1). Electrocardiography, cerebral magnetic resonance imaging and testing on human immunodeficiency remained inconspicuous. In the electrophysiological examination repetitive stimulation revealed a significant decrement of 35\% (reference $<10 \%$; Figure 1). Additionally, pathological spontaneous activity and a myogenic pattern on electromyography were observed in several muscles (Table 2), which supported the diagnosis of a concomitant polymyositis. Unfortunately, a muscle biopsy of the left quadriceps muscle was performed after initiation of corticosteroid treatment as an outpatient. Histopathological examination revealed partly atrophic and atrophic angulated muscle fibers as well as nuclei clumps consistent with a neurogenic muscular atrophy. There was a predominant but not selective atrophy of type-II-muscle fibers. Immunohistochemistry did not show endomysial inflammatory infiltrates or expression of MHC class I-antigen on muscle fibers. No congophilic amyloid was found (Figure 2). The findings were compatible with, however, not typical for MG. Thus the diagnosis of PM, suggested by electromyographical results, could not be confirmed in muscle biopsy. Moreover, the

*Corresponding author: Esther Annegret Pelzer, Department of Neurology, University Hospital Cologne, Kerpener Str. 62, 50937 Cologne, Germany, Tel: +49221-4726-620; E-mail: esther.pelzer@uk-koeln.de

Received June 15, 2012; Accepted June 27, 2012; Published June 30, 2012

Citation: Pelzer EA, Galldiks N, Eggers C, Brunn A, Fink GR, et al. (2012) Evidence of Spontaneous Activity in Two Cases of Severe Myasthenia Gravis. Neurol Neurophysiol 3:136. doi:10.4172/2155-9562.1000136

Copyright: ( 2012 Pelzer EA, et al. This is an open-access article distributed under the terms of the Creative Commons Attribution License, which permits unrestricted use, distribution, and reproduction in any medium, provided the original author and source are credited. 
Citation: Pelzer EA, Galldiks N, Eggers C, Brunn A, Fink GR, et al. (2012) Evidence of Spontaneous Activity in Two Cases of Severe Myasthenia Gravis. J Neurol Neurophysiol 3:136. doi:10.4172/2155-9562.1000136

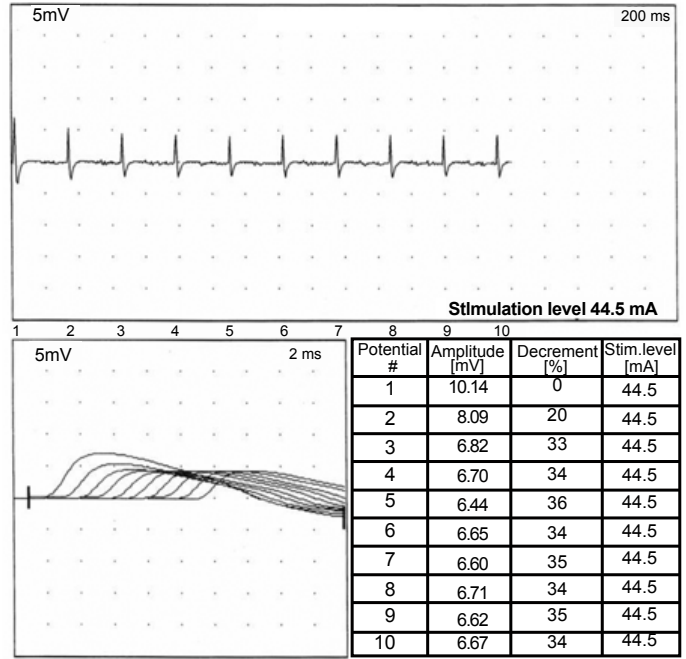

Figure 1: Severe Myasthenic reaction in patient (\#1). The figure shows a pathological decrement of $36 \%$ after repetitive stimulation of the accessory nerve (reference < 10\%; amplification: $5 \mathrm{mV}$; time base: $0.2 \mathrm{~s}$ ).

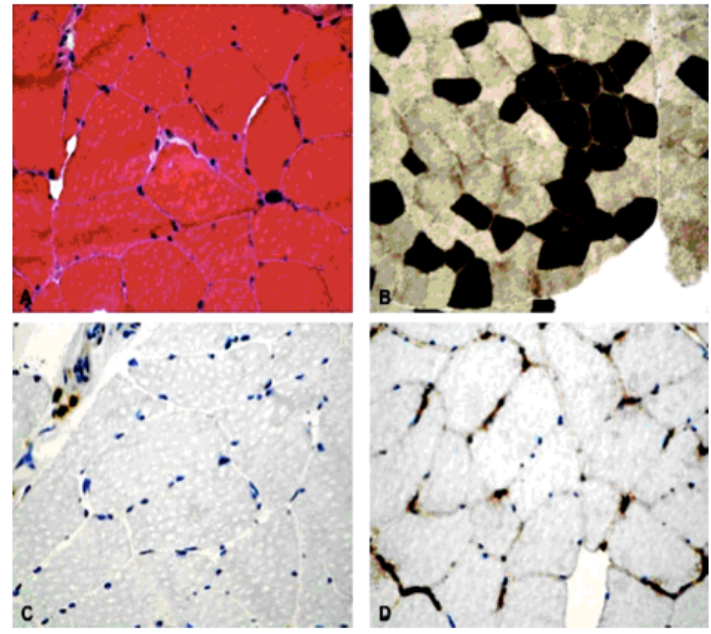

Figure 2: Biopsy of quadriceps muscle (patient \#1)

A: Partly atrophic and atrophic angulated muscle fibers and nuclei clumps indicative for a chronic and slowly progressive neurogenic muscular atrophy. No inflammatory infiltrates in the endomysial tissue. H\&E staining, magnification $\times 400$.

B: Myofibrillar ATPase ( $\mathrm{pH}$ 9.4) shows partly atrophic muscle fibers of both fiber types with predominance of type two fibers. Enzyme histochemistry with mATPase at $\mathrm{pH}$ 9.4, magnification $\times 200$.

C: Three T-cells adjacent to a blood vessel in the perimysial tissue. No evidence of endomysial inflammatory infiltrates. Immunohistochemistry with anti-CD3 and slight counterstain with hemalum, magnification $\times 400$. $\mathrm{D}$ : Physiological expression of MHC class I-antigen on endomysial capillaries while sarcolemmal upregulation is not noted. Immunohistochemistry with anti-MHC class I- antigen and slight counterstain with hemalum, magnification $x 400$.

magetic resonance imaging of the proximal leg did not demonstrate a peri- or intramuscular oedema. Anti-Jo-1 antibodies were absent. Esophageal manometry revealed a hypomotile reaction. The computed tomography of the chest and abdomen showed a thymoma or thymus carcinoma. On thymectomy, a type-A-thymus (Type II) with a calibre of $6 \mathrm{~cm}$ with small malignant areas was found corresponding to the clinical diagnosis of MG. Symptomatic therapy with pyridostigmine and immune suppression with prednisolone and azathioprine were initiated which controlled the symptoms. Unfortunately, the patient developed a severe infection of the sternum postoperatively and several complications during immunosuppression, including widespread spondylodiscitis of the thoracic spine, which necessitated operative treatment and long-term mechanical ventilation for several weeks. The patient improved slowly over the course of several months and was ambulatory at one year with a significant improvement of clinical and neurophysiological findings (Figure 3). The diagnosis of myasthenia gravis was confirmed by combination of myasthenic symptoms, improvement under medication and diagnostic findings (as illustrated above). Because of the muscle pain of the proximal limbs and the pathological spontaneous activity in the electromyographical the possibility of a concomitant myositis such as PM has to be discussed.

\section{Patient \#2}

A74-yearold man was referred to our hospital with slowlyprogressive weakness of the masseter muscles, dysphagia, and weakness of limbgirdle muscles. His past medical history included arterial hypertension, diabetes mellitus type 2, prostate hyperplasia, and Helicobacter pyloripositive chronic gastritis. The neurological examination revealed dysarthria, dysphagia, and paresis of limb-girdle muscles. The deep tendon reflexes were normal. Laboratory investigations showed increased creatine kinase levels (286 U/l) and significantly increased AChR-antibody levels $(23 \mathrm{nmol} / \mathrm{l})$. MuSK-antibody levels, however, were normal $(<0.5 \mathrm{nmol} / \mathrm{l}$; Table 1$)$. Anti-Jo-1 antibodies were also negative. Electromyographical examination showed a decrement of $20 \%$, indicating a myasthenic reaction (reference $<10 \%$ ). Pathological spontaneous activity, a myogenic pattern and a muscle edema in the MRI of the left shoulder were indicative of PM (Table 2). In contrast, a muscle biopsy of the left deltoid revealed signs of chronic neurogenic atrophy and myopathic features. Selective type-II muscle atrophy was found, however, no signs of inflammation typical for myositis were detected. Further examinations (doppler- and duplex sonography, electroencephalography, and electrocardiography) did not show any pathological findings. Total-body $\left({ }^{18} \mathrm{~F}\right)$ fluorodeoxyglucose positronemission-tomography was performed. No signs of malignant disease, especially a thymoma, were found. Treatement with azathioprine (100 $\mathrm{mg} / \mathrm{d})$, pyridostigmine $(240 \mathrm{mg} / \mathrm{d})$, and methylpredisolone $(60 \mathrm{mg} / \mathrm{d})$

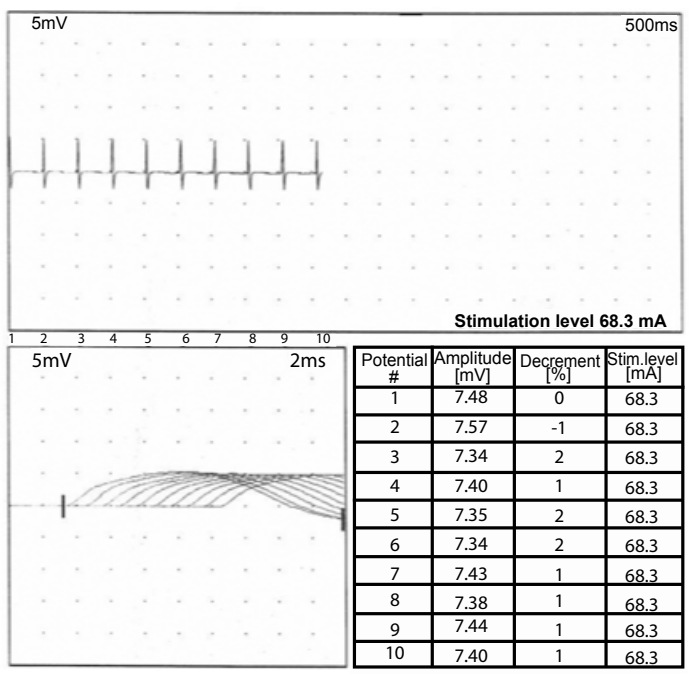

Figure 3: Myasthenic reaction in clinical remission in patient (\#1). Repetitive stimulation with a normalisation of decrement $<10 \%$ (amplification: $5 \mathrm{mV}$; time base: $0.5 \mathrm{~s})$. 


\begin{tabular}{|l|l|l|l|l|}
\hline Patient & $\begin{array}{l}\text { Titer of Acetylcho- } \\
\text { line receptor Anti- } \\
\text { bodies (Reference } \\
<0.2 \mathrm{nmol} / \mathrm{l})\end{array}$ & $\begin{array}{l}\text { Titer of MuSK } \\
\text { antibodies } \\
\text { (Reference } \\
<10)\end{array}$ & $\begin{array}{l}\begin{array}{l}\text { Titer of Titin } \\
\text { Antibodies } \\
\text { Serum: }\end{array} \\
\text { Negative) }\end{array}$ & $\begin{array}{l}\text { Creatinine kinase } \\
(\mathrm{m}<190 \mathrm{U} / \mathrm{l} ; \mathrm{w}< \\
170 \mathrm{U} / \mathrm{l})\end{array}$ \\
\hline$\# 1(\mathrm{w})$ & 110 & 5.49 & Negative & Normal $(81 \mathrm{U} / \mathrm{l})$ \\
\hline$\# 2(\mathrm{~m})$ & 23 & $<0.5$ & Negative & Increased $(286 \mathrm{U} / \mathrm{l})$ \\
\hline
\end{tabular}

Table 1: Laboratory findings.

\begin{tabular}{|c|c|c|c|c|c|c|}
\hline Patient & $\begin{array}{l}\text { Decrement } \\
\text { (Trapezius) }\end{array}$ & Muscle & $\begin{array}{l}\text { Fibrila- } \\
\text { tions }\end{array}$ & \begin{tabular}{|l|} 
Positive \\
sharp waves
\end{tabular} & $\begin{array}{l}\text { Form of ac- } \\
\text { tion potential }\end{array}$ & $\begin{array}{l}\text { EMG pat- } \\
\text { tern }\end{array}$ \\
\hline \multirow[t]{3}{*}{ \#1 } & $35 \%$ & $\begin{array}{l}\text { Right } \\
\text { biceps br. }\end{array}$ & + & + & Polyph. & Myogenic \\
\hline & & Left deltoid & + & + & Bi-/Polyph. & Myogenic \\
\hline & & $\begin{array}{l}\text { Right vas- } \\
\text { tus med. }\end{array}$ & - & - & Bi-/Polyph. & Myogenic \\
\hline \multirow[t]{8}{*}{ \#2 } & $20 \%$ & $\begin{array}{l}\text { Right } \\
\text { orbicularis } \\
\text { oris }\end{array}$ & - & - & Bi-/Polyph. & Myogenic \\
\hline & & $\begin{array}{l}\text { Right } \\
\text { trapezius }\end{array}$ & - & - & Bi-/Polyph. & Myogenic \\
\hline & & $\begin{array}{l}\text { Left trape- } \\
\text { zius }\end{array}$ & - & - & Biph. & Myogenic \\
\hline & & $\begin{array}{l}\text { Right } \\
\text { deltoid }\end{array}$ & - & - & Bi-/Polyph. & Myogenic \\
\hline & & $\begin{array}{l}\text { Right inter- } \\
\text { osseus } 1\end{array}$ & - & - & Bi-/Polyph. & Myogenic \\
\hline & & $\begin{array}{l}\text { Paraspinal } \\
\text { muscles, } \\
\text { thoracic } \\
\text { level }\end{array}$ & ++ & ++ & - & - \\
\hline & & $\begin{array}{l}\text { Right vas- } \\
\text { tus lat. }\end{array}$ & - & - & Bi-/Polyph. & Myogenic \\
\hline & & $\begin{array}{l}\text { Right ante- } \\
\text { rior tribal }\end{array}$ & - & - & Bi-/Polyph. & Myogenic \\
\hline
\end{tabular}

Table 2: Electromyographical findings at admission.

had no long lasting effect. The course of the disease worsened with progressive dysarthria and dysphagia, walking became impossible. After five immunoadsorption sessions, symptoms improved for several months. In summary pathological spontaneous activity, the myogenic pattern and the muscle edema in the magnetic resonance imaging (MRI) perturbed the classical diagnosis of MG.

\section{Discussion}

These two cases show difficulties in determining the exact differential diagnosis between myasthenia gravis and polymyositis because of the simultaneous appearance of myasthenic and myopathic symptoms in clinical and diagnostic results. In summary, it appears possible that there is a concomitant clinical mainfestation of MG and myositis (see introduction).

However, there is still no clear knowledge concerning the pathophysiological cascade and the overlap of these two diseases. By having a closer look PM and MG can both be induced by autoimmune mechanisms. Autoantibodies against human tissue may play a significant role, such as histidyl-t-RNA synthethase antibodies for $\mathrm{PM}$ and AChR- or MuSK-auto-antibodies in MG. In MG, polyclonal autoantibodies (e.g. IgG) can be found, which bind to the postsynaptic acetylcholine receptors. These acetylcholine autoantibodies can be found in $80 \%$ of patients with a generalized form of MG. In 10 to $20 \%$ of patients with generalised MG, these AChR autoantibodies are not found (seronegativity). In $40-70 \%$ of MG without AChR-antibodies antibodies against MuSK are present. A possible correlation between the titer of AChR autoantibodies and the presence of spontaneous activity and myopathic features in the electromyographical investigation has to be mentioned. Regarding genetics, about $90 \%$ of patients with PM are genetic carriers of HLA-DR-3. Genes between B8 and DR3 on this haplotype are frequently associated with autoimmune diseases, typically also found in MG. Furthermore, paraneoplastic causes of both diseases are possible with an appearance of either MG or PM or both at the same time (Patient \#1). In PM, the histidyl-RNA synthethase is one of the main areas of attack of autoantibodies, also known as antiJo-1-antibodies. The amino-acryl-synthethases are responsible for the specific charging of transfer-RNA with amino acids. This characteristic reaction of IgG (positive anti-Jo-antibodies) in human serum or plasma is seen in $40 \%$ of the patients with dermato- or PM [10,11]. In our patients, anti-Jo-1-antibodies were not present.

In summary, differentiation between these two entities of muscle diseases seems clinically and electromyographically not that easy as initially hypothesized, especially in serious disease courses of myasthenia gravis. Perhaps even overlaps between MG and PM exist, thus further diagnostic and therapeutic strategies may be demanded. With these two cases, we want to make clinicians to be attentive to have a closer look on electromyographical changes in patients with severe MG. In the presence of AChR antibodies there should be no doubt of the diagnosis of MG. As the presented cases show, pathological EMG patterns do not exclude the diagnosis of MG. Therefore further studies on the correlation of myogenic changes, the AChR titer and the extent of decrement in the repetitive stimulation have to be performed.

\section{References}

1. Jaretzki A 3rd, Barohn RJ, Ernstoff RM, Kaminski HJ, Keesey JC, et al (2000) Myasthenia gravis: recommendations for clinical research standards. Task Force of the Medical Scientific Advisory Board of the Myasthenia Gravis Foundation of America. Ann Thorac Surg 70: 327-334.

2. Bertorini TE (1998) Inflammatory myopathies [polymyositis, dermatomyositis and inclusion body myositis]. Compr Ther 24: 494-502.

3. Hill CL, Zhang Y, Sigurgeirsson B, Pukkala E, Mellemkjaer L, et al. (2001) Frequency of specific cancer types in dermatomyositis and polymyositis: a population based study. Lancet 357: 96-100.

4. Yamaguchi Y, Sakurai Y, Mannen T, Shimizu J (2000) Rapidly progressive polymyositis with elevated antiacetylcholine receptor antibody activity. Intern Med 39: 1108-1110.

5. De Reuck J, Thiery E, De Coster W, Van Der Eecken H (1976) Myasthenic syndrome in polymyositis. Eur Neurol 14: 275-284.

6. Raschilas F, Mouthon L, Andre MH, Azorin J, Couvelard A, et al. (1999) Concomitant polymyositis and myasthenia gravis reveal malignant thymoma. A case report and review of the literature. Ann Med Interne (Paris) 150: 370-373.

7. Lee $A B$, Thurston RS (2008) Malignant thymoma and myasthenia gravis presenting as polymyositis: a case report. J La State Med Soc 160: 286-288.

8. Hausmanowa-Petrusewicz I, Blaszczyk M, Jablonska S (1995) Coexistence of scleromyositis associated with PM-Scl antibody and myasthenia. Neuromuscul Disord 5: 145-147.

9. Hengstman GJ, Drost G, Wagenaar M, van Engelen BG (2006) Persistent increased risk for thymoma in myasthenia gravis associated with myositis. Muscle Nerve 34: 251-252.

10. Bohan A, Peter JB (1975) Polymyositis and dermatomyositis (first of two parts). N Engl J Med 292: 344-347.

11. Bohan A, Peter JB (1975) Polymyositis and dermatomyositis (second of two parts). N Engl J Med 292: 403-407. 